\title{
The dynamic processes of hydrothermal activity related to seismicity in the Tatun Volcano group of Taiwan: Evidences from multi-observations
}

\author{
C.C. $\mathrm{FU}^{1 *}$, L.C. $\mathrm{LEE}^{1}$, AND C.H. LIN ${ }^{1}$
}

${ }^{1}$ Institute of Earth Sciences, Academia Sinica, Taiwan (*correspondence: ccfu@earth.sinica.edu.tw)

Taiwan is tectonically situated in a terrain resulting from the oblique collision between the Philippine Sea plate (PSP) and the Eurasian plate (EP). The continuous observations of gamma rays at the YMSG station are recorded in volcanic area in north Taiwan for the volcanic and seismic studies. A number of anomalous high gamma-rays at certain times can be found. It is noted that significant increase of gamma rays can be observed a few days to a few weeks before the earthquakes, which occurred in northeastern Taiwan. These earthquakes are usually related to the subduction of PSP beneath EP to the north along the subduction zone in northern Taiwan (e.g., $M_{L}=6.4$ April 20, 2015). A further comparison of multi-observations through gamma-ray data, local geomagnetic variations and micro-earthquakes in Tatun Volcanic group (TVG) area may imply that the process of local rock fracture for hydrothermal gas and fluid migration, potentially associated with the pre-seismic stress. The prestress of seismic event was accompanied by inflation around the TVG, suggestive of a pressure increase in the volcanic system. It is inferred that the increase in gamma rays is related to the development of a micro-fractured zone. The pressure increase in the volcanic system is attributed to the intrusion of hydrothermal fluids, which is supported by an observed increase in geomagnetic variations. The increase in shallow micro-earthquakes are considered to be generated by the effect of fluid-filled cracks. 